\title{
In vitro bovine embryo production in a synthetic medium: Embryo development, cryosurvival, and establishment of pregnancy
}

\author{
D. Moreno ${ }^{a, b}$, A. Neira ${ }^{a}$, L. Dubreil ${ }^{c}$, L. Liegeois ${ }^{b}$, S. Destrumelle ${ }^{a}$, \\ S. Michaud ${ }^{a}$, C. Thorin ${ }^{a}$, L. Briand-Amirat ${ }^{a}$, D. Bencharif ${ }^{a}$, D. Tainturier ${ }^{a}$, \\ ${ }^{a}$ Laboratory of Biotechnology and Pathology of Reproduction, Nantes-Atlantic National College of Veterinary Medicine, Food Science \\ and Engineering, Oniris, Nantes, France \\ ${ }^{\mathrm{b}}$ Gènes Diffusion SAS, Douai, France \\ ${ }^{\mathrm{c}}$ UMR 703, PAnTher, INRA Oniris, Nantes-Atlantic National College of Veterinary Medicine, Food Science and Engineering, Nantes, \\ France
}

\section{A R T I C L E I N F O}

\section{Article history:}

Received 1 August 2014

Received in revised form 12 March 2015

Accepted 15 April 2015

\section{Keywords:}

Synthetic medium

Embryo culture

Growth factor

Cytokine

Hyaluronan

\begin{abstract}
A B S T R A C T
The aim of this study was to develop an in vitro embryo culture medium without either fetal calf serum or BSA, using various growth factors and cytokines (GFs-CYKs; IGF-I, IGF-II, bFGF, LIF, GM-CSF, TGF- $\beta 1$, and PDGF-BB), and other molecules with surfactant and embryotrophic properties, such as recombinant albumin (RA) and hyaluronan (HA). The first part of the study was dedicated to define the best combination of GFs-CYKs + RA + HA for optimal embryonic development. Next, we compared development rates and embryo quality (inner cell mass [ICM]-to-total cell number [TCN] ratio), and postthaw survival and hatching rates using this synthetic medium (T1) and a control medium: synthetic oviduct fluid + BSA + ITS (insulin, transferrin, and selenium). The blastocyst rates were significantly higher with $\mathrm{T} 1$ than those with the control at 7 and 8 days after fertilization. There was no significant difference in TCN or the ICM/TCN ratio between the two treatments. Survival and hatching rates 48 hours after thawing were similar for both treatments. Finally, nine embryo transfers were conducted using fresh and previously frozen Day-7 blastocysts to evaluate the in vivo viability of embryos produced in this synthetic medium; four gestations were obtained from six fresh embryos and one gestation from three frozen embryos. In conclusion, the fetal calf serum and BSA-free medium, supplemented with GFs-CYKs + RA + HA, improved embryo development and gave comparable ICM/TCN ratios and postthaw survival rates to the control with BSA. Fresh and frozen embryos produced in this medium are viable for embryo transfer. This fully synthetic method of embryo culture is a useful means of reducing the risk of disease transmission via embryo transfer.
\end{abstract}

(c) 2015 Published by Elsevier Inc.

\section{Introduction}

The majority of embryo culture media contain fetal calf serum (FCS) or BSA; however, the former has been shown to have a negative effect on embryo quality. These embryos

\footnotetext{
* Corresponding author. Tel.: +332 40687715; fax: +33240687748.

E-mail address: daniel.tainturier@oniris-nantes.fr (D. Tainturier).
}

have a high lipid content in the trophoblast and inner cell mass (ICM) cells [1]; this cytoplasmic accumulation of lipids can affect the cryotolerance of embryos [2]. In some cases, this resulted in large offspring syndrome, characterized by high birth weight, prolonged gestation, frequent dystocia, and elevated abortion rates [3]. In addition, the use of animal-derived proteins in culture media increases the risk of disease transmission via in vitro 
embryo production. There have been several attempts to develop synthetic media, with no negative impact on early embryonic development, using molecules with embryotrophic properties such as growth factors (GFs) and cytokines (CYKs), glycosaminoglycans, or recombinant proteins.

Numerous GFs and CYKs are involved in embryonic development [4]. Growth factors including insulinlike growth factors I and II (IGFs I and II), basic fibroblastic growth factor (bFGF), transforming growth factor $\beta 1$ (TGF- $\beta 1$ ), and platelet derived growth factor-BB (PDGF-BB) and CYKs such as granulocyte-macrophage colonystimulating factor (GM-CSF) and leukemia inhibitory factor (LIF) are produced by the endometrium and trophoblast during embryonic development [5]. These GFs and CYKs have been used to supplement embryonic culture media. Insulinlike growth factor I stimulates embryonic development in bovine embryos [6] and increases gestation and calving rates of dairy cows [7]. Insulinlike growth factor II decreases the apoptosis index in mouse embryos [4]. Fibroblast growth factor enhances the development of bovine embryos produced in vitro [8], promotes migratory activity in ovine trophoblast cells [9], and increases the production of interferon-tau in bovine trophectoderm (TE), an essential component for the establishment and maintenance of pregnancy in cattle and sheep $[10,11]$. Leukemia inhibitory factor increases the number of ICM cells in bovine embryos produced in vitro [12]. Transforming growth factor $\beta 1$ increases blastocyst and implantation rates of mouse embryos in vitro [13]. Granulocyte-macrophage colony-stimulating factor increases blastocyst rates, the number of ICM cells, and pregnancy rates of in vitro bovine embryos [14]. Several GFs and CYKs have also been used in association [15].

The glycosaminoglycan, hyaluronan (HA), is found in abundance in the follicular, oviductal, and uterine fluid of cattle $[16,17]$. It plays an important role in embryonic development; HA receptors (CD44) are expressed on the surface of bovine embryos at different stages of development [18]. The addition of HA to embryo culture media has been shown to increase the number of bovine embryos that develop to the blastocyst stage $[18,19]$ and improve survival rates of in vitro bovine embryos after vitrification [19].

Recombinant proteins, such as recombinant albumin (RA), have been used to replace BSA in culture media to reduce the risk of disease transmission via embryo transfer. When combined with HA, RA increases the percentage of blastocysts and hatchings after cryopreservation of in vitro bovine embryos [20].

In a previous study in our laboratory [5], we selected six recombinant GFs and CYKs (GFs-CYKs; IGF-I, IGF-II, bFGF, LIF, TGF- $\beta 1$, and GM-CSF) on the basis of their known pleiotropic effects on embryonic development [21]. Two different concentrations of each GF and CYK (50 ng/mL and $100 \mathrm{ng} / \mathrm{mL}$ ) were tested on embryonic development. Similar results were found with the majority of the GFs-CYKs; only TGF- $\beta 1$ showed a slight tendency to enhance embryo development at a concentration of $100 \mathrm{ng} / \mathrm{mL}$ in comparison with $50 \mathrm{ng} / \mathrm{mL}$; however, the differences were not significant. Subsequent tests to determine the effect of each GF and CYK separately were therefore conducted with a concentration of $50 \mathrm{ng} / \mathrm{mL}$.
Insulinlike growth factor I, bFGF, TGF- $\beta 1$, and GM-CSF were found to significantly improve the transition to the blastocyst stage. Finally, a combination of six GFs and CYKs (IGF-I, IGF-II, bFGF, LIF, TGF- $\beta 1$, and GM-CSF) was tested. The study reported that the use of a combination of compounds in the embryo culture medium is more effective than synthetic oviduct fluid (SOF) medium alone and as effective as FCS for in vitro embryo development [5]. In that particular study, each of the GF and CYK was diluted with a low concentration of BSA to promote embryo development and to reduce the risk of adherence to the plastic dishes.

The aim of the present study was to assess the effect of replacing the BSA in the GFs-CYKs medium (IGF-I, IGF-II, bFGF, TGF- $\beta 1$, GM-CSF, and LIF), with other molecules with surfactant and embryotrophic properties, such as RA and HA, on the hypothesis that the effect of the GFs-CYKs is the result of an interaction between several different molecules [21]. We then attempted to optimize this medium by supplementation with TGF- $\beta 1(100 \mathrm{ng} / \mathrm{mL})$ and another growth factor (PDGF) that has shown beneficial effects on embryo development [22]. Finally, we tested the efficacy of this novel medium in vivo.

We used a control medium containing SOF supplemented with BSA and ITS (insulin, transferrin, and selenium) for all the experiments. This latter culture medium is commonly used as an alternative serum-free culture system [2]. For each part of the study, the media were compared in terms of development and hatching rates. For the third part, we also recorded the ICM-to-total cell number (TCN) ratio and cryosurvival. Finally, fresh and frozen Day-7 blastocysts were transferred to evaluate the in vivo viability of embryos produced in this synthetic medium.

\section{Materials and methods}

\subsection{Chemicals}

All chemicals were purchased from Sigma-Aldrich (Saint-Quentin-Fallavier, France), unless otherwise specified. The GFs and CYKs (IGF-I, IGF-II, bFGF, LIF, TGF- $\beta 1$, GM-CSF, and PDGF-BB) were human recombinants. Insulinlike growth factor I was solubilized using 0.1-M acetic acid at a concentration of $0.5 \mathrm{mg} / \mathrm{mL}$. Insulinlike growth factor II was solubilized using 1-M acetic acid at a concentration of $10 \mu \mathrm{g} /$ mL. Basic FGF was solubilized using PBS with $0.1 \%$ polyvinylpyrrolidone (PVP) at a concentration of $25 \mu \mathrm{g} / \mathrm{mL}$. Leukemia inhibitory factor was solubilized using PBS with $0.1 \%$ PVP at a concentration of $1 \mu \mathrm{g} / \mathrm{mL}$. Transforming growth factor $\beta 1$ was solubilized using $4-\mathrm{mM} \mathrm{HCl}$ at a concentration of $1 \mu \mathrm{g} / \mathrm{mL}$. Granulocyte-macrophage colony-stimulating factor was solubilized using PBS with $0.1 \%$ PVP at a concentration of $1 \mu \mathrm{g} / \mathrm{mL}$. Platelet-derived growth factor-BB was solubilized using sterile water for embryo transfer at a concentration of $5 \mu \mathrm{g} / \mathrm{mL}$. They were all stored at $-80^{\circ} \mathrm{C}$.

\subsection{In vitro embryo production}

\subsubsection{Oocyte collection and in vitro maturation}

Ovaries were collected at the abattoir postmortem and stored in PBS at $37{ }^{\circ} \mathrm{C}$ before transportation for 1 hour to 
the laboratory. Cumulus-oocyte complexes were aspirated from follicles with a diameter of 2 to $8 \mathrm{~mm}$. Cumulusoocyte complexes with a homogeneous cytoplasm and compact cumulus oophorus and corona radiata were selected and washed in HEPES-buffered TCM-199 medium supplemented with $0.4 \%$ BSA (Fraction V). They were then matured in $500 \mu \mathrm{L}$ of TCM-199 medium supplemented with $60 \mu \mathrm{g} / \mathrm{mL}$ of penicillin, $60 \mu \mathrm{g} / \mathrm{mL}$ of streptomycin, and $10 \mathrm{ng} / \mathrm{mL}$ of EGF for 24 hours at $38.5{ }^{\circ} \mathrm{C}$ and $5 \% \mathrm{CO}_{2}$ in humidified air.

\subsubsection{In vitro fertilization}

After maturation, the oocytes were transferred into $500 \mu \mathrm{L}$ of IVF-Tyrode's albumin lactate pyruvate medium supplemented with $6 \mathrm{mg} / \mathrm{mL}$ of fatty acid-free BSA with $1.7 \mathrm{IU} / \mathrm{mL}$ of heparin; the oocytes were then moved to another $250 \mu \mathrm{L}$ of the same medium. Spermatozoa were taken from the frozen-thawed semen of a breeding bull. The straws were thawed in a water bath at $37{ }^{\circ} \mathrm{C}$ for 30 seconds, and the motile spermatozoa were selected via discontinuous density gradient centrifugation (40\%-80\%) BoviPure (Nidacon, Sweden). The semen was analyzed with a Hamilton Thorne IVOS (IMV Technologies, Saint-Ouen-Sur-Iton, France) and diluted to a final concentration of $2 \times 10^{6}$ spermatozoa/ $\mathrm{mL}$. The spermatozoa were then incubated with the oocytes in the IVF-Tyrode's albumin lactate pyruvate medium for 18 hours at $38.5{ }^{\circ} \mathrm{C}$ and $5 \% \mathrm{CO}_{2}$ in humidified air.

\subsubsection{In vitro culture}

After fertilization, the cumulus cells were removed by vortex. The presumptive zygotes were divided into groups and cultured in 30- $\mu \mathrm{L}$ droplets of SOF supplemented according to the protocol. A mean of 23 embryos were cultured per droplet. The droplets were preserved under mineral oil in a humidified atmosphere of $5 \% \mathrm{CO}_{2}, 5 \% \mathrm{O}_{2}$, and $90 \% \mathrm{~N}_{2}$ at $38.5^{\circ} \mathrm{C}$.

\subsection{Preparation of a culture medium with GFs and CYKs but without BSA and FCS}

\subsubsection{Experiment 1: Effect of GFs and CYKs in the absence of $B S A$}

Presumptive zygotes obtained from 1026 oocytes were randomly assigned to one of two different treatments: (1) $50 \mathrm{ng} / \mathrm{mL}$ (IGF-I, IGF-II, bFGF, TGF- $\beta 1$, GM-CSF, and LIF) and (2) $0.4 \% \mathrm{BSA}+5 \mu \mathrm{g} / \mathrm{mL}$ of insulin, $5 \mu \mathrm{g} / \mathrm{mL}$ of transferrin, and $5 \mathrm{ng} / \mathrm{mL}$ of selenium (ITS; control). Development rates were compared at 7,8 , and 9 days post fertilization (dpf). Hatching rates were compared at $9 \mathrm{dpf}$.

\subsubsection{Experiment 2: Effect of adding recombinant albumin to a medium containing GFs and CYKS}

Presumptive zygotes obtained from 961 oocytes were randomly assigned to one of three different treatments: (1) $50 \mathrm{ng} / \mathrm{mL}$ of GFs and CYKs, (2) I $+1.5 \mathrm{mg} / \mathrm{mL}$ of RA (A9731; Sigma-Aldrich), and (3) control (BSA + ITS). Development rates were compared at 7, 8, and $9 \mathrm{dpf}$. Hatching rates were compared at $9 \mathrm{dpf}$.

\subsubsection{Experiment 3: Effect of adding $H A$ to a medium containing GFs-CYKs $+R A$}

Presumptive zygotes obtained from 835 oocytes were randomly assigned to one of two different treatments: (1) $50 \mathrm{ng} / \mathrm{mL}$ of GFs-CYKs + RA + $0.5 \mathrm{mg} / \mathrm{mL}$ of HA (R\&D Systems, Abingdon, UK) and (2) control (BSA + ITS). Development rates were compared at 7, 8, and $9 \mathrm{dpf}$. Hatching rates were compared at $9 \mathrm{dpf}$.

\subsection{Optimization of the synthetic medium developed in the} previous step with the addition of other GFs

\subsubsection{Experiment 4: Effect of adding $100 \mathrm{ng} / \mathrm{mL}$ of TGF- $\beta 1$ to a} medium containing GFs-CYKs $+R A+H A$

Presumptive zygotes obtained from 1043 oocytes were randomly assigned to one of two different treatments: (1) $50 \mathrm{ng} / \mathrm{mL}$ of GFs-CYKs (IGF-I, IGF-II, bFGF, LIF, GM-CSF) and $100 \mathrm{ng} / \mathrm{mL}$ of TGF- $\beta 1+\mathrm{RA}+\mathrm{HA}$ and (2) control (SOF + BSA). Development rates were compared at 7, 8, and $9 \mathrm{dpf}$. Hatching rates were compared at $9 \mathrm{dpf}$.

\subsubsection{Experiment 5: Effect of adding PDGF-BB to a medium containing GFs-CYKs (100 ng/mL of TGF- $\beta 1)+R A+H A$}

Presumptive zygotes obtained from 778 oocytes were randomly assigned to one of three different treatments: (1) GFs-CYKs (double TGF- $\beta 1$ ) + RA + HA; (2) I + 50 ng/mL of PDGF-BB, and (3) control (BSA + ITS). Development rates were compared at 7,8 , and $9 \mathrm{dpf}$. Hatching rates were compared at $9 \mathrm{dpf}$.

\subsection{Validation of the synthetic medium containing} GFs-CYKs $+R A+H A$ developed in the previous step

2.5.1. Experiment 6: Effect of the synthetic medium containing GFs-CYKs + RA + HA in comparison with the control medium

Presumptive zygotes obtained from 1070 oocytes were randomly assigned to one of two treatments: (1) GFs and CYKs (double TGF- $\beta 1+$ PDGF) + RA + HA and (2) control (BSA + ITS). Development rates were compared at 7, 8, and $9 \mathrm{dpf}$. Hatching rates were compared at $9 \mathrm{dpf}$. Inner cell mass-to-TCN ratio was compared at 7 and $8 \mathrm{dpf}$. The survival and hatching rates were compared at 12,24 , and 48 hours after thawing.

\subsubsection{Differential staining of inner cell mass and trophectoderm cells}

To determine the number of ICM and TE cells, hatched embryos were selected at $8 \mathrm{dpf}$. The embryos were fixed in $4 \%$ paraformaldehyde for 1 hour at room temperature. They were then washed three times in PBS containing 0.2\% PVP and transferred to a solution of PBS supplemented with $10 \%$ FCS and $0.2 \%$ Triton X-100 (S1) for 1 hour at room temperature. Differential staining was performed using a goat SOX-2 antibody (Santa Cruz Biotechnology, Santa Cruz, CA, USA; $1: 500$ in S1) overnight at $4{ }^{\circ} \mathrm{C}$. After washing once in S1 and twice in PBS-PVP for 5 minutes each, the embryos were incubated in S1 supplemented with the secondary antibody, Alexa Fluor 555 donkey antigoat IgG antibody (Life Technologies; 1:1000), and the nuclear marker, DRAQ5 (1:1000), for 2 hours at room temperature. After washing twice in PBS-PVP, labeled embryos were mounted 
in Lab-Tek chambered coverglasses in PBS-PVP to preserve their structure. Confocal imaging was performed with an LSM780 confocal microscope with $561 \mathrm{~nm}$ and $633 \mathrm{~nm}$ lasers (Zeiss, Marly-le-Roi, France). Z stacks were performed throughout the thickness of the embryos; threedimensional reconstructions were made from stacks using Fiji software [23]. Inner cell mass and TE cells were counted using the Fiji 3D nucleus counter plugin.

\subsubsection{Cryopreservation of embryos}

At $7 \mathrm{dpf}$, blastocysts were cryopreserved using a slowfreezing procedure. Embryos were washed three times in a holding medium (IMV Technologies) and placed in a $50-\mu \mathrm{L}$ droplet of freezing extender (IMV Technologies freezing extender [1.5 mol/L ethylene glycol]) at room temperature for 10 minutes. During which time, the embryos were loaded into $0.25-\mathrm{mL}$ straws (IMV Technologies). The straws were placed in a programmable freezer, HUBER HS40 (Fisher Scientific, France), at $-7{ }^{\circ} \mathrm{C}$ for 5 minutes. Seeding was then induced, and the straws were maintained for a further 5 minutes at $-7{ }^{\circ} \mathrm{C}$ and then cooled at $0.3^{\circ} \mathrm{C} / \mathrm{min}$ to $-35^{\circ} \mathrm{C}$. Finally, the straws were plunged into liquid nitrogen.

For thawing, the straws were exposed to room air for 5 seconds before being plunged into a water bath at $25^{\circ} \mathrm{C}$ for 30 seconds and emptied into a Petri dish. The embryos were washed three times in a holding medium and then cultured in SOF medium supplemented with 5\% FCS. The survival and hatching rates were evaluated at 12,24 , and 48 hours after the start of culture.

\subsubsection{Estrous synchronization and embryo transfer}

Heifers aged between 22 and 29 months were synchronized with a vaginal progesterone diffusion system, PRID DELTA 1.55 g (Ceva, France). The implant was inserted 16 days before embryo transfer and removed 7 days later. An injection of prostaglandin, Enzaprost (Ceva, France), was administered 24 hours before removing the implant, and an injection of PMSG (Chrono-gest 400; Intervet, France) was administered at the time of removal. The embryo transfers were performed 9 days after removal of the implant. Blastocysts cultured in the synthetic medium up to the seventh day after IVF were placed in the holding medium and mounted in $0.25-\mathrm{mL}$ straws (IMV Technologies), before being transferred to the inner uterine horn of the heifers on the same side as the ovary with the CL. Gestation was diagnosed by rectal palpation and ultrasound between 30 and 65 days of gestation.

\subsection{Statistical analysis}

Blastocyst and hatching rates and survival after cryopreservation were analyzed using a linear mixed-effects model. The ICM/TCN ratios were analyzed using a one-way ANOVA; all tests were performed with R software [24]. The residuals for each model were identically and independently distributed as $\mathrm{N}\left(0, \sigma^{2}\right)$; the random effects were distributed as $\mathrm{N}\left(0, \Sigma^{2}\right)\left(\Sigma^{2}\right.$ : variance covariance matrix of a random effect) [25]. Differences were considered significant at $\mathrm{P}<0.05$.

\section{Results}

3.1. Preparation of a culture medium with growth factors and cytokines but without BSA and FCS

\subsubsection{Experiment 1: (1) growth factors and cytokines; control} $(B S A+I T S)$

After seven replicates of IVF, blastocyst rates obtained with treatment 1 were significantly lower than those with the control at 7, 8, and $9 \mathrm{dpf}$ (at $7 \mathrm{dpf}$ : $4.3 \pm 1.7 \%$ vs. $17.1 \pm 2.3 \%$; at $8 \mathrm{dpf}$ : $11.5 \pm 2.1 \%$ vs. $24.4 \pm 2.9 \%$; and at 9 dpf: $21.9 \pm 2.4 \%$ vs. $39.5 \pm 2.9 \%$, respectively). Hatching rates were lower with treatment 1 than those with the control $(4.9 \pm 1.6 \%$ and $13.9 \pm 1.7 \%$, respectively $)$.

\subsubsection{Experiment 2: (1) GFs and CYKs; (2) GFs-CYKS + RA; control}

After five replicates of IVF, blastocyst rates obtained with treatments 1 and 2 were significantly lower than those with the control at 7 and $8 \mathrm{dpf}$ (at $7 \mathrm{dpf}$ : [1]: $16.0 \pm 2.1 \%$; [2]: $16.7 \pm 1.8 \%$; and [control]: $23.6 \pm 1.5$; and at 8 dpf: [1] $21.4 \pm 2.9 \%$; [2]: $19.1 \pm 2.3 \%$; and (control): $30.9 \pm 2.2 \% ; \mathrm{P}<0.05$ ). There were no significant differences in blastocyst and hatching rates between the treatments at 9 dpf: (1): $30.3 \pm 3.1 \%$ and $9.2 \% \pm 1.8 \%$; (2): $29.2 \pm 2.9 \%$ and $8.2 \pm 2.1 \%$; and (control): $31.8 \pm 3.2 \%$ and $10.7 \pm 3.0 \%$, respectively, $(\mathrm{P}>0.05)$.

\subsubsection{Experiment 3: (1) GFs-CYKs $+R A+H A$; control}

After five replicates of IVF, there were no significant differences in blastocyst rates between the treatments at 7 and $8 \mathrm{dpf}$ (at $7 \mathrm{dpf}[1]$ : $31.3 \pm 3.4 \%$ and control: $33.5 \pm 4.0 \%$ and at $8 \mathrm{dpf}[1]$ : $38.1 \pm 3.2 \%$ and [control]: $40.8 \pm 4.4 \%)$. At 9 dpf, blastocyst and hatching rates were comparable: (1): $40.4 \pm 2.9 \%$ and $15.2 \pm 1.9 \%$; (control): $41.7 \pm 4.1 \%$ and $16.7 \pm 1.6 \%$, respectively, $(\mathrm{P}>0.05)$.

\subsection{Optimization of the synthetic medium developed in the} previous step with the addition of other GFs

\subsubsection{Experiment 4: (1) GFs-CYKs (double TGF- $\beta 1)+R A+H A$; control}

After six replicates of IVF, the blastocyst rates were not significantly different between treatment 1 and the control: at $7 \mathrm{dpf}(30.2 \pm 3.0 \%$ vs. $22.9 \pm 4.8 \%), 8 \mathrm{dpf}(37.4 \pm 2.0 \%$ vs. $29.6 \pm 5.1 \%)$, and $9 \mathrm{dpf}(39.2 \pm 2.3 \%$ vs. $32.6 \pm 4.1 \%$, respectively; $\mathrm{P}>0.05)$. No significant differences were observed in the hatching rates at $9 \mathrm{dpf}$ between treatment $1(15.1 \pm 2.6 \%)$ and the control $(13.8 \pm 2.9 \%)$.

3.2.2. Experiment 5: (1) GFs-CYKs (double TGF- $\beta 1)+R A+H A$; (2) I + PDGF-BB; control

After four replicates of IVF, there was a significant difference in blastocyst rates between the three treatments at 7 dpf: (1): $24.9 \pm 1.6 \%$; (2): $30.8 \pm 1.9 \%$, and (control): $17.6 \pm 2.6 \%(\mathrm{P}<0.05)$. Blastocyst rates were significantly higher at $8 \mathrm{dpf}$ with treatment 2, containing PDGF-BB: $34.6 \pm 1.4 \%$, compared with treatment $1: 29.3 \pm 2.0 \%$ and with the control: $25.4 \pm 4.1 \%$. At $9 \mathrm{dpf}$, blastocyst and hatching rates were higher with treatment 2 : $36.9 \pm 1.7 \%$ and $17.5 \pm 1.3 \%$ compared with treatment $1: 30.5 \pm 1.9 \%$ 
Table 1

Effect of two treatments on blastocyst rates and hatched blastocyst yield at 7 and 8 days after fertilization.

\begin{tabular}{|c|c|c|c|c|c|}
\hline \multirow[t]{2}{*}{ Treatment } & \multirow[t]{2}{*}{$\mathrm{n}$} & \multicolumn{4}{|c|}{ Blastocyst rates (\%, mean \pm SEM) from 10 replicates } \\
\hline & & Day 7 & Day 8 & Day 9 & HB/Day 9 \\
\hline SOF + BSA + ITS (control) & 563 & $19.1 \pm 1.6^{\mathrm{a}}$ & $28.1 \pm 2.6^{\mathrm{a}}$ & $30.3 \pm 2.9^{\mathrm{a}}$ & $19.3 \pm 5.7^{\mathrm{a}}$ \\
\hline $\mathrm{SOF}+\mathrm{GFs}-\mathrm{CYKs}+\mathrm{RA}+\mathrm{HA}$ & 507 & $30.9 \pm 2.6^{b}$ & $36.0 \pm 2.4^{b}$ & $38.2 \pm 2.7^{b}$ & $24.6 \pm 5.4^{\mathrm{a}}$ \\
\hline
\end{tabular}

$\mathrm{n}=$ number of oocytes

${ }^{\mathrm{a}, \mathrm{b}}$ Columns with different letters are significantly different $(\mathrm{P}<0.05)$.

Abbreviations: GFs-CYKs, growth factors-cytokines; HA, hyaluronan; HB, hatched blastocyst; ITS, insulin, transferrin, and selenium; RA, recombinant albumin; SOF, synthetic oviduct fluid.

and $12.5 \pm 1.6 \%$ and with the control: $27.5 \pm 3.7 \%$ and $13.1 \pm 1.7 \%$, respectively.

3.3. Validation of the synthetic medium containing GFs-CYKs (double TGF- $\beta 1+P D G F-B B)+R A+H A$, developed in the previous step

\subsubsection{Assessment of blastocyst development}

After 10 replicates of IVF, at 7, 8 , and $9 \mathrm{dpf}$, the blastocyst rates were higher with treatment 1 than with the control; however, hatching rates at $9 \mathrm{dpf}$ were similar between the mediums; the results are summarized in Table 1.

\subsubsection{Assessment of total cell number and ICM/TCN ratio}

No significant differences were observed in the TCN and ICM/TCN ratio at $8 \mathrm{dpf}$, between treatments (Fig. 1, Table 2).

\subsubsection{Assessment of survival and hatching rates after cryopreservation}

There were no significant differences in survival and hatching rates after cryopreservation between treatments $(\mathrm{P}>0.05$; Table 3$)$.

\subsubsection{Assessment of in vivo viability of embryos produced in} the synthetic medium

Preliminary trials, based on the transfer of fresh and frozen embryos at the blastocyst stage produced in the synthetic medium, resulted in four gestations from six fresh embryos and one gestation from three frozen embryos.

\section{Discussion}

A previous study, in our laboratory, reported that the synergistic use of several GFs and CYKs (IGF-I, IGF-II, bFGF, LIF, TGF- $\beta 1$, and GM-CSF) at $50 \mathrm{ng} / \mathrm{mL}$ each [5] has beneficial effects on the development of bovine embryos. However, in that study, all the GFs and CYKs were solubilized in the presence of a low concentration of BSA.

The aim of this study was to develop an in vitro embryo culture medium that is completely BSA-free, with the addition of various GFs and CYKs and other molecules with surfactant and embryotrophic properties, such as RA and $\mathrm{HA}$, to reduce the risk of disease transmission via embryo transfer. The GFs and CYKs were therefore solubilized with synthetic products.

Growth factors and CYKs are typically found in FCS [26]. Their expression has been reported in preimplanted embryos in cattle [27], and they are generally added to the basal culture medium to increase cell proliferation and stimulate specific cell functions in vitro [28]. The beneficial effects of various GFs and CYKs in embryo culture media have been reported in different species $[4,8,9,29,30]$.

The mechanisms by which GFs and CYKs enhance embryo development are not known [6]. Possible mechanisms include stimulation of cell multiplication and the formation of the blastocele, inhibition of apoptosis, stimulation of interferon-tau production, and reduced interferon-gamma production [4,6,11-14]. The GFs and CYKs may act in synergy on the same cellular function and may have identical effects on embryo development [31]. For example, bFGF stimulates the expression of $\alpha$ receptors,
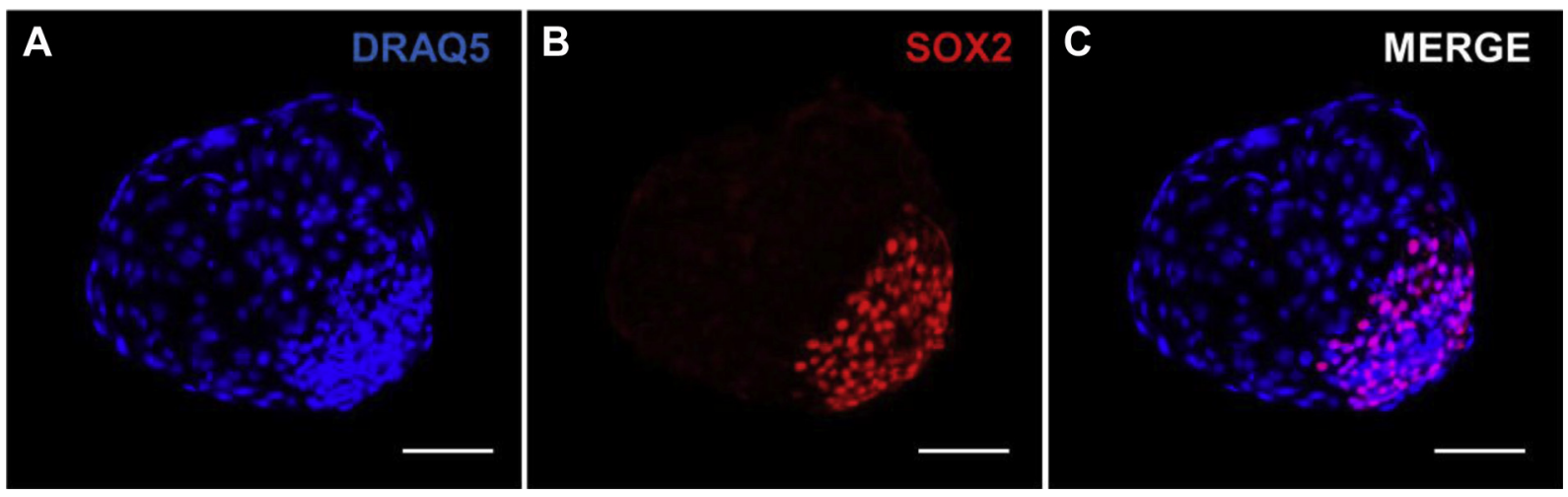

Fig. 1. Differential staining of inner cell mass (ICM) and trophectoderm (TE) cells of hatching bovine embryos at 8 days post fertilization. (A) DRAQ5: TCN; (B) SOX2: ICM; (C) overlay. Scale bar: $50 \mu \mathrm{m}$. 
Table 2

Effect of two treatments on inner cell mass (ICM) and trophectoderm (TE) cell number at 8 days after fertilization.

\begin{tabular}{|c|c|c|c|c|c|}
\hline \multirow[t]{2}{*}{ Treatment } & \multirow[t]{2}{*}{$\mathrm{n}$} & \multirow{2}{*}{$\frac{\text { Total }}{\text { Cell number }}$} & \multirow{2}{*}{$\frac{\text { ICM }}{\text { Cell number }}$} & \multirow{2}{*}{$\frac{\mathrm{TE}}{\text { Cell number }}$} & \multirow[t]{2}{*}{ ICM/total (\%) } \\
\hline & & & & & \\
\hline SOF + BSA + ITS (control) & 9 & $203.8 \pm 7.1$ & $60.9 \pm 3.5$ & $142.9 \pm 4.2$ & 29.9 \\
\hline $\mathrm{SOF}+\mathrm{GFs}-\mathrm{CYKs}+\mathrm{RA}+\mathrm{HA}$ & 13 & $214.4 \pm 7.7$ & $67.1 \pm 2.8$ & $147.3 \pm 5.8$ & 31.3 \\
\hline
\end{tabular}

$\mathrm{n}=$ number of embryos stained.

Abbreviations: GFs-CYKs, growth factors-cytokines; HA, hyaluronan; ITS, insulin, transferrin, and selenium; RA, recombinant albumin; SOF, synthetic oviduct fluid.

which are required for interaction with PDGF-BB [32]. Platelet-derived growth factor-BB and hyaluronic acid act in synergy to stimulate cellular differentiation [33].

In experiment 1 , we used the same association of GFs-CYKs as that defined by Neira et al. [5] but without the addition of BSA. This culture medium gave lower blastocyst rates than the control medium (SOF + BSA + ITS) at 7, 8, and $9 \mathrm{dpf}$. The viscosity of the medium was suboptimal without BSA, and embryo manipulation became difficult. Recombinant albumin was added to resolve this issue. The latter is free from any potential biological contamination [20], and it plays a role in the transport of steroids, fatty acids, and thyroid hormones. Lane et al. [20] reported equivalent blastocyst rates using a medium supplemented with $2.5 \mathrm{mg} / \mathrm{mL}$ of RA and $0.125 \mathrm{mg} / \mathrm{mL}$ of HA when compared with a medium supplemented with BSA. After previous experiments, a minimal concentration of RA $(1.5 \mathrm{mg} / \mathrm{mL})$ was chosen to obtain optimal viscosity.

In experiment 2 , we therefore added $\mathrm{RA}(1.5 \mathrm{mg} / \mathrm{mL})$ to the medium with the GFs and CYKs; this resolved the viscosity problems, and we observed a comparable rate of development at $9 \mathrm{dpf}$. However, development between 7 and $8 \mathrm{dpf}$ was delayed compared with the control medium (SOF + BSA + ITS). Hyaluronan was added for its beneficial effects in bovine embryo culture in association with RA [20].

Hyaluronan is one of the most abundant substances in follicular, oviduct, and uterine fluid $[17,34]$. It is involved in several processes mediated through interaction with matrix components, cell proliferation, and cell differentiation [35]. Hyaluronan and its receptors are thought to be involved in the regulation of GFs [36]. Various concentrations of HA have been tested in previous studies. For example, it has been shown that implantation rates and fetal development are increased by the addition of a low concentration of $\mathrm{HA}(0.5 \mathrm{mg} / \mathrm{mL})$ in the culture media during embryo transfer in mice [37]. Stojkovic et al. [35] reported that a high concentration $(6 \mathrm{mg} / \mathrm{mL})$ increased the viscosity of the culture medium and improved development rates and cell numbers in bovine embryos produced in vitro. Block et al. [19] found that the addition of $1 \mathrm{mg} / \mathrm{mL}$ of HA to the culture medium increased blastocyst rates at $7 \mathrm{dpf}$ compared to a culture medium without HA, but no effect was reported at lower concentrations ( 0.1 and $0.5 \mathrm{mg} / \mathrm{mL}$ ). In our study, HA was added at a concentration of $0.5 \mathrm{mg} / \mathrm{mL}$.

In experiment 3, with this completely synthetic medium containing GFs and CYKs (IGF-I, IGF-II, bFGF, LIF, TGF- $\beta 1$, and GM-CSF) $50 \mathrm{ng} / \mathrm{mL}+\mathrm{RA}+\mathrm{HA}$, we obtained comparable development rates to the control medium $(\mathrm{SOF}+\mathrm{BSA}+\mathrm{ITS})$ at 7, 8, and $9 \mathrm{dpf}$ [38]. These results confirm a previous study in which the association of RA and HA gave similar blastocyst rates to a medium with BSA [20].

In experiment 4, we tried to optimize the synthetic medium (GFs-CYKs + RA + HA) by doubling the concentration of TGF- $\beta 1$ ( $100 \mathrm{ng} / \mathrm{mL}$ ), which confirmed previous findings in which this GF showed a slight tendency to enhance embryo development at a concentration of $100 \mathrm{ng} / \mathrm{mL}$ compared with $50 \mathrm{ng} / \mathrm{mL}$. A preliminary report of these results was presented at the International Embryo Transfer Society Meeting 2014 [39].

In experiment 5 , we tested the effects of supplementing this last medium with another growth factor with embryotrophic properties (PDGF-BB). The resulting development rates were higher than those of the same medium without PDGF-BB and of the control. These results confirm previous studies on the beneficial effect of this GF on embryonic development [22]. A composition that gave the best development rates compared to the control medium (BSA + ITS) was finally reached.

The final study, experiment 6 , tested this last completely synthetic medium on embryo development, cellular proliferation and differentiation, cryosurvival, and pregnancy rates. Superior blastocyst development rates were obtained in comparison with the control (BSA-ITS) at 7, 8, and 9 dpf. These results confirm previous findings [5], in which the association of GFs and CYKs (IGF-I, IGF-II, bFGF, LIF, TGF- $\beta 1$, and GM-CSF) improved the potential for embryo development in comparison with SOF alone or SOF and FCS

Table 3

Effect of two treatments on survival and hatching rates after thawing.

\begin{tabular}{|c|c|c|c|c|c|c|c|}
\hline \multirow[t]{2}{*}{ Treatment } & \multirow[t]{2}{*}{$\mathrm{n}$} & \multicolumn{2}{|c|}{$12 \mathrm{~h}$ After thawing } & \multicolumn{2}{|c|}{$24 \mathrm{~h}$ After thawing } & \multicolumn{2}{|c|}{$48 \mathrm{~h}$ After thawing } \\
\hline & & Surviving $\mathrm{n}(\%)$ & Hatching $\mathrm{n}(\%)$ & Surviving $\mathrm{n}(\%)$ & Hatching $\mathrm{n}(\%)$ & Surviving $\mathrm{n}(\%)$ & Hatching $\mathrm{n}(\%)$ \\
\hline $\mathrm{SOF}+\mathrm{BSA}+\mathrm{ITS}$ (control) & 32 & $21(65.6)$ & $6(18.7)$ & $21(65.6)$ & $6(18.7)$ & $21(65.6)$ & $8(25.0)$ \\
\hline $\mathrm{SOF}+\mathrm{GFs}-\mathrm{CYKs}+\mathrm{RA}+\mathrm{HA}$ & 34 & $21(61.7)$ & $4(11.8)$ & $21(61.7)$ & $4(11.8)$ & $21(61.7)$ & $7(20.5)$ \\
\hline
\end{tabular}

$\mathrm{n}=$ number of embryos freeze.

Abbreviations: GFs-CYKs, growth factors-cytokines; HA, hyaluronan; ITS, insulin, transferrin, and selenium; RA, recombinant albumin; SOF, synthetic oviduct fluid. 
combined. In the latter study, all the GFs and CYKs were diluted in the presence of BSA to reduce the risk of adherence to the plastic dishes. In our study, we used the same combination of GFs and CYKs but replaced the BSA with RA and HA; we also added a double concentration of TGF- $\beta 1$ (100 ng/mL) and a new growth factor with embryotrophic properties (PDGF-BB). The results obtained confirm that TGF- $\beta 1$ has a superior effect on embryo development at a concentration of $100 \mathrm{ng} / \mathrm{mL}$, as suggested in a previous study [5]. They also confirm the beneficial effect of PDGFBB on embryo development [22] and a possible synergy between PDGF-BB and HA [33].

This association gave comparable results to the control for TCN, ICM/TCN ratios, and postthaw survival rates. With the synthetic medium, cell proliferation and differentiation were similar to the control medium. And the embryos produced in this synthetic medium tolerate cryopreservation as well as those produced in the presence of BSA.

Finally, four gestations (66\%) were obtained from six fresh embryo transfers and one gestation (33\%) was obtained from three frozen embryo transfers. These rates are comparable to previous studies that obtained average gestation rates of $50.5 \%$ [40] and $41.8 \%$ [41] with fresh IVF embryos, and $27.7 \%$ [40] with frozen embryos.

This is a fully synthetic method of embryo culture; it presents a valuable tool for reducing the risk of disease transmission via embryo transfer. This medium promotes embryo development and has no negative effects on embryo quality and cryosurvival. The next step will be to replace the BSA in the fertilization medium to achieve a completely synthetic means of producing bovine embryos in vitro.

\section{Acknowledgments}

Diego Moreno is a PhD student financially supported by Genes Diffusion and Association Nationale pour la Recherche Technique. The authors would like to thank Michelle Boutte and Karine Leroux from Genes Diffusion for their technical assistance.

\section{Competing Interests}

None of the authors have any conflicts of interest to declare.

\section{References}

[1] Abe H, Hoshi H. Evaluation of bovine embryos produced in high performance serum-free media. J Reprod Dev 2003;49:193-202.

[2] George F, Daniaux C, Genicot G, Verhaeghe B, Lambert P, Donnay I. Set up of a serum-free culture system for bovine embryos: embryo development and quality before and after transient transfer. Theriogenology 2008;69:612-23.

[3] Lazzari G, Wrenzycki C, Herrmann D, Duchi R, Kruip T, Niemannn H, et al. Cellular and molecular deviations in bovine in vitro produced embryos are related to the large offspring syndrome. Biol Reprod 2002;67:767-75.

[4] Desai N, Kattal N, AbdelHafez F, Szeptycki-Lawson J, Goldfarb J. Granulocyte-macrophage colony stimulating factor (GM-CSF) and co-culture can affect post-thaw development and apoptosis in cryopreserved embryos. J Assist Reprod Genet 2007;24:215-22.
[5] Neira JA, Tainturier D, Peña MA, Martal J. Effect of the association of IGF-I, IGF-II, bFGF, TGF- $\beta 1$, GM-CSF, and LIF on the development of bovine embryos produced in vitro. Theriogenology 2010;73:595-604.

[6] Bonilla AQ Ozawa M, Hansen PJ. Timing and dependence upon mitogen-activated protein kinase signaling for pro-developmental actions of insulin-like growth factor 1 on the preimplantation bovine embryo. Growth Horm IGF Res 2011;215:107-11.

[7] Block J, Drost M, Monson RL, Rutledge JJ, Rivera RM, Paula-Lopes FF, et al. Timing and dependence upon mitogen-activated protein kinase signaling for pro-developmental actions of insulin-like growth factor 1 on the preimplantation bovine embryo. J Anim Sci 2003;81:1590-602.

[8] Fields SD, Hansen PJ, Ealy AD. Fibroblast growth factor requirements for in vitro development of bovine embryos. Theriogenology 2011; 75:1466-75.

[9] Yang QE, Giassetti MI, Ealy AD. Fibroblast growth factors activate mitogen-activated protein kinase pathways to promote migration in ovine trophoblast cells. Reproduction 2011;141:707-14.

[10] Michael D, Alvarez I, Ocon O, Powell A, Talbot N, Johnson S, et al. Fibroblast growth factor-2 is expressed by the bovine uterus and stimulates interferon-production in bovine trophectoderm. Endocrinology 2006; 147:3571-9.

[11] Yang QE, Johnson SE, Ealy AD. Protein kinase C delta mediates fibroblast growth factor-2-induced interferon-tau expression in bovine trophoblast. Biol Reprod 2011;84:933-43.

[12] Sirisathien S, Hernandez-Fonseca HJ, Bosch P, Hollet BR, Lott JD, Brackett BG. Effect of leukemia inhibitory factor on bovine embryos produced in vitro under chemically defined conditions. Theriogenology 2003;59:1751-63.

[13] Luo S, Yin HN, Li SW. Effect of TGF-beta1 on embryo implantation and development in mice in vitro. J Sichuan Univ 2010;41: 265-8.

[14] Loureiro B, Bonilla L, Block J, Fear J, Bonilla A, Hansen P. Colonystimulating factor 2 (CSF-2) improves development and post-transfer survival of bovine embryos produced in vitro. Endocrinology 2009;150:5046-54.

[15] Larson RC, Ignotz GG, Currie WB. Transforming growth factor beta and basic fibroblast growth factor synergistically promote early bovine embryo development during the fourth cell cycle. Mol Reprod Dev 1992;33:432-5.

[16] Block J, Hansen P, Loureiro B, Bonilla L. Improving post-transfer survival of bovine embryos produced in vitro: actions of insulinlike growth factor-1, colony stimulating factor-2 and hyaluronan. Theriogenology 2011;76:1602-9.

[17] Lee CN, Ax RL. Concentration and composition of glycoaminoglycans in the female bovine reproductive tract. J Dairy Sci 1984;67:2006-9.

[18] Furnus C, Valcarcel A, Dulout F, Errecalde A. The hyaluronic acid receptor $(C D 44)$ is expressed in bovine oocytes and early stage embryos. Theriogenology 2003;60:1633-44.

[19] Block J, Bonilla L, Hansen PJ. Effect of addition of hyaluronan to embryo culture medium on survival of bovine embryos in vitro following vitrification and establishment of pregnancy after transfer to recipients. Theriogenology 2009;71:1063-71.

[20] Lane M, Maybach JM, Hooper K, Hasler JF, Gardner DK. Cryo-survival and development of bovine blastocysts are enhanced by culture with recombinant albumin and hyaluronan. Mol Reprod Dev 2003; 64:70-8.

[21] Martal J, Chêne N, Camous S, Huynh L, Lantier F, Hermier P. Recent developments and potentialities for reducing embryo mortality in ruminants: the role of IFN- $\tau$ and other cytokines in early pregnancy. Reprod Fertil Dev 1997;9:355-80.

[22] Eckert J, Niemann H. Effects of platelet derived growth factor (PDGF) on the in vitro production of bovine embryos in protein-free media. Theriogenology 1996;46:307-20.

[23] Schindelin J, Arganda-Carreras I, Frise E, Kaynig V, Longair M, Pietzsch T, et al. Fiji: an open-source platform for biological-image analysis. Nat Methods 2012;9:676-82.

[24] R Core Team. R: a language and environment for statistical computing. R Foundation for Statistical Computing. Vienna: Austria. http://www.R-project.org/, 2013. Accessed: March 10, 2015.

[25] Pinheiro JC, Bates MD. Mixed-effects models in S and S-plus. Springer -Verlag New York Inc, New York, NY, USA; 2000.

[26] Brunner D, Frank J, Appl H, Schöffl H, Pfaller W, Gstraunthaler G. Serum-free cell culture: the serum-free media interactive online database. Altex 2010;27:53-62.

[27] Watson AJ, Hogan A, Hahnel A, Wiemer KE, Schultz GA. Expression of growth factor ligand and receptor genes in the preimplantation bovine embryo. Mol Reprod Dev 1992;31:87-95. 
[28] Van der Valk J, Brunner D, De Smet K, Fex Svenningsen A Honegger P, Knudsen LE, et al. Optimization of chemically defined cell culture media-replacing fetal bovine serum in mammalian in vitro methods. Toxicol In Vitro 2010;24:1053-63.

[29] Cui XS, Jeong YJ, Jun JH, Kim NH. Insulin-like growth factor-I alters apoptosis related genes and reduces apoptosis in porcine parthenotes developing in vitro. Theriogenology 2005;63:1070-80.

[30] Fabian D, Il'kova G, Rehak P, Czikkova S, Baran V, Koppel J. Inhibitory effect of IGF-I on induced apoptosis in mouse preimplantation embryos cultured in vitro. Theriogenology 2004;61:745-55.

[31] Thibault C, Levasseur MC. Reproduction in mammals and man, INRA Edit. Paris: Ellipses; 2001. p. 366-89.

[32] Heldin $\mathrm{CH}$, Westermark B. Mechanism of action and in vivo role of platelet-derived growth factor. Physiol Rev 1999;79:1284-316.

[33] Klominek J, Robert KH, Hjerpe A, Wikstrom B, Gahrton G. Serumdependent growth patterns of two, newly established human mesothelioma cell lines. Cancer Res 1989;49:6118-22.

[34] Suchanek E, Simunic V, Juretic D, Grizelj V. Follicular fluid contents of hyaluronic acid, follicle-stimulating hormone and steroids relative to the success of in vitro fertilization of human oocytes. Fertil Steril 1994;62:347-52.

[35] Stojkovic M, Kölle S, Peinl S, Stojkovic P, Zakhartchenko V, Thompson JG, et al. Effects of high concentrations of hyaluronan in culture medium on development and survival rates of fresh and frozen-thawed bovine embryos produced in vitro. Reproduction 2002;124:141-53.

[36] Furnus C, De Matos D, Martinez AG. Effect of hyaluronic acid on development of in vitro produced bovine embryos. Theriogenology 1998;49:1489-99.

[37] Gardner DK, Rodriegez-Martinez H. Fetal development after transfer is increased by replacing protein with the glycosaminoglycan hyaluronan for mouse embryo culture and transfer. Hum Reprod 1999;14:2575-80.

[38] Moreno-Garcia D, Neira A, Liegeois L, Amirat-Briand L, Destrumelle $\mathrm{S}$, Boutte $\mathrm{M}$, et al. In vitro production of bovine embryos in a serum and BSA free medium. Reprod Domest Anim 2013; 48:103.

[39] Moreno D, Neira A, Dubreil L, Liegeois L, Destrumelle S, AmiratBriand L, et al. Development of a synthetic medium for the in vitro culture of bovine embryos. Reprod Fertil Dev 2014;26:154.

[40] Block J, Bonilla L, Hansen PJ. Efficacy of in vitro embryo transfer in lactating dairy cows using fresh or vitrified embryos produced in a novel embryo culture medium. J Dairy Sci 2010;93: 5234-42.

[41] Block J, Hansen PJ. Interaction between season and culture with insulin-like growth factor-1 on survival of in vitro produced embryos following transfer to lactating dairy cows. Theriogenology 2007;67:1518-29. 